КЛИНИКО-МОРФОЛОГИЧЕСКАЯ ХАРАКТЕРИСТИКА КОЖИ

У ДЕТЕЙ С АТОПИЧЕСКИМ ДЕРМАТИТОМ

'Бедин П.Г. (ntf2011@yandex.by),'ЛяликовC.A. (lalikov@tut.by),

'Басинский B.А. (basinsk@gmail.com),2МаршалэкАнджей (amars@ump.edu.pl),

'Штабинская T.T. (shtabik@list.ru),'Алексинский B.C. (aleksinski.w.s@gmail.com)

уУО «Гродненский государственный медицинский университет», Гродно, Беларусь

${ }^{2}$ Медицинский университет имени Людвига Ридигера, Быдгощ, Польша

\begin{abstract}
Введение. Атопический дерматит (АД) - актуальная проблема педиатрии ввиду широкой распространённости данного заболевания.

Цель - дать клинико-морфологическую характеристику кожи у детей с АД и выявить ее взаимосвязь с клиническими проявлениями.

Материал и методы. Проведено морфологическое и иммуногистохимическое исследование 27 биоптатов атопической и 48 - неатопической кожи.

Результаты. Экспрессию $\operatorname{IgE}$ и CD8 в эпидермисе следует отнести к благоприятному признаку, так как они сопровождаются меньшей интенсивностью зуда и площадью поражения кожи ( $p=0,03$ в обоих случаях). В 100\% образцов эритематозно-сквамозной формы в дерме был инфильтрат CD4+, что чаще, чем при других клинических формах (p=0,01). Динамика SCORAD была больше у детей без инфильтрации CD4 клетками эпидермиса $(p=0,04)$, что связано с большей исходной суммой баллов $\operatorname{SCORAD}(p=0,02)$.

Выводы. Морфологические и иммуногистохимические маркеры существенным образом связаны с клиническими особенностями АД.
\end{abstract}

Ключевые слова: атопический дерматит, кожа, морфология, дети.

\section{Введение}

Атопический дерматит (АД) - хроническое аллергическое заболевание, развивающееся у лиц с генетической предрасположенностью к атопии, имеющее рецидивирующее течение с возрастными особенностями клинических проявлений и характеризующееся экссудативными и/или лихеноидными высыпаниями, повышением уровня сывороточного IgE и гиперчувствительностью к специфическим (аллергенам) и неспецифическим раздражителям [1]. АД - самое частое заболевание кожи у лиц детского возраста. По данным Всемирной аллергологической организации (WAO), распространённость АД среди детей составляет $15-30 \%$. Заболеваемость АД медленно, но неуклонно увеличивается, и за последние три десятилетия в промышленно развитых странах выросла в 2-3 раза [2]. Сре-

ставили 521 миллион евро в год. Годовое бремя 1 пациента для экономики Германии составляет 4400 евро [2].

Известно, что заболевание развивается на фоне генетической предрасположенности, в основе которой находится мутация в гене филаггрина - барьерного белка кожи [3].

Строение кожи и особенности морфологической картины при АД в общем достаточно хорошо изучены и освещены в фундаментальных руководствах, посвящённых морфологии кожи $[6,7]$. Однако данные о связи клинико-лабораторных показателей и особенностей иммунопатологических процессов, на наш взгляд, скудные и фрагментарные $[8,9]$. Это определило цель дать клинико-морфологическую характеристику кожи у детей с АД и выявить ее взаимосвязь с клиническими проявлениями.
\end{abstract} ди взрослых распространённость АД составляет 1-3\% [3]. У детей Гродненского региона заболеваемость как общая, так и первичная, в настоящее время сохраняется на стабильном уровне $(825,25 \quad(95 \%$ ДИ $(729,26-921,24)$ на 100 тысяч детей в возрасте 0-14 лет) с тенденцией к увеличению [4]. Вероятно, эта тенденция будет стабильной вследствие действующих социально-экономических и медико-демографических факторов [5].

АД - серьёзная медико-социальная проблема [2]. Это связано с тем, что он причиняет страдания не только пациенту, но и членам его семьи. Заболевание наносит существенный экономический ущерб. Подсчитано, что затраты на лечение детей, страдающих АД, превосходят затраты на терапию инсулинозависимого сахарного диабета или бронхиальной астмы в детском возрасте [3]. Так, в Великобритании затраты со-

\section{Материал и методы}

Обследованы 27 детей с АД, медиана возраста которых составила 7,0 лет, интерквартильный размах - 2,0-11,0 лет. Оценка SCORAD на момент поступления составила 47,0 $(31,0-67,0)$ баллов.

Диагностика и терапия заболевания проводились в соответствии с действующим стандартом [10]. Кроме АД, учитывалось наличие сопутствующих заболеваний. Тяжесть АД оценивалась с использованием шкалы SCORAD, состоящей из 3 блоков: A - распространённость кожного процесса, В - наличие и выраженность морфологических элементов, C - субъективные жалобы (интенсивность зуда и нарушение сна). Блок «В» включает оценку интенсивности сухости непоражённой кожи и характеристику пораженных участков: наличие экскориаций, папул, лихенификации и эритемы [11]. Дерма- 
тит считался лёгким при сумме баллов менее 20, средней тяжести - 20-39, тяжёлым - 40 и более. Относительная динамика высчитывалась как разность значений индекса SCORAD до лечения и после его завершения, делённая на значение индекса до лечения и умноженная на 100\%. Дети включались в исследование с согласия родителя (законного представителя) при наличии АД. Критерии не включения в исследование: наличие на момент обследования острых инфекционных заболеваний.

Для сравнения были использованы 48 образцов кожи, полученных от детей, сопоставимых по возрасту с детьми основной группы, но без клинических признаков АД и гнойно-воспалительных заболеваний кожи. Образцы были взяты в процессе выполнения планового оперативного лечения разных хирургических заболеваний (грыжесечение, аппендэктомия и др.).

Биопсию кожи производили пациентам с АД до применения топических и/или системных глюкокортикостероидов, топических ингибиторов кальциневрина. Кожу забирали на границе видимо неизменённой и поражённой кожи. Материал фиксировали в $10 \%$ растворе нейтрального формалина в течение 24 часов. После фиксации он проводился через спирты восходящей концентрации в гистопроцессоре фирмы Leika, заливался в парафин. Из полученных блоков изготавливали срезы толщиной 5-6 мкм, которые после депарафинизации и регидратации окрашивали гематоксилином и эозином.

При микроскопическом исследовании биоптата кожи определялись наличие, выраженность и характер воспалительного процесса, полуколичественно (в баллах) оценивали состав и выраженность клеточного инфильтрата, признаки васкулита, акантоза, спонгиоза, гиперкератоза, склероза, отёка дермы и внутриклеточного отёка изменений баллы суммировали.

Иммуногистохимическое исследование проводили на серийных парафиновых срезах толщиной 3-4 мкм, помещенных на предметные стекла с высокой адгезивной способностью. Депарафинизацию и демаскировку антигенов выполняли с помощью PTLink. Блокирование эндогенной пероксидазы осуществляли 3\% раствором перекиси водорода. Для устранения неспецифического эпидермиса. Для общей оценки выраженности

связывания реагентов с тканевыми компонентами наносили на срезы 5\% раствор бычьего сывороточного альбумина на фосфатном буфере. Срезы инкубировали с первичными антителами во влажной камере. Описание антител приведено в таблице 1.

В качестве вторичных антител и пероксидазного комплекса использовали универсальную визуализирующую систему на полимерной основе к мышиным и кроличьим антителам (фирма «Dako», Дания). Для визуализации реакции применяли раствор диаминобензидина $\mathrm{DAB}+$ (фирма «Dako», Дания). Ядра клеток докрашивали гематоксилином Майера. Просветление и заключение срезов осуществляли последовательно в спиртах восходящей концентрации и трех порциях ксилола. В качестве положительного контроля антигена использовали срезы тканей, рекомендуемые фирмой-производителем.

Статистическая обработка материала проводилась с помощью пакета прикладных программ Statistica 10.0 (SN AXAR207F394425FA-Q) непараметрическими методами. Коэффициент корреляции рассчитывался по Спирмену. Сравнение двух независимых переменных вели с помощью теста Манна-Уитни. При сравнении трёх и более независимых переменных использовали медианный тест, при попарном сравнении переменных в этом случае применяли тест Краскела-Уоллиса (критерий z). Для сравнения долей использовали точный критерий Фишера (Fisher exact test, two-tailed). Данные приведены в виде «медиана (нижняя квартиль - верхняя квартиль)». Для долей (\%) рассчитывался 95\% доверительный интервал (95\% ДИ) по формулам Клоппера-Пирсона (Clopper-Pearson interval).

\section{Результаты и обсуждение}

Морфологически кожа пациентов с АД характеризовалась наличием в верхних слоях дермы воспалительного инфильтрата, представленного в основном лимфоидными клетками с примесью плазмоцитов. Преимущественно инфильтрат локализовался в периваскулярных зонах и захватывал стенку сосуда. Помимо того, в дерме выявлялись разной степени отёк и склеротические изменения. Структура эпителиального пласта сохранялась, хотя в ряде случаев отмечались расширение рогового слоя, акантоз и спонгиоз с внутриклеточным отеком эпителия.

В группе срав-

Таблица 1. - Характеристика антител, использованных для иммуногистохимического исследования

\begin{tabular}{|c|c|c|c|c|}
\hline Антитело & Фирма и номер & Разведение & $\begin{array}{c}\text { Время и } \mathrm{t}^{\circ} \text { инкубации } \\
\text { с первичным } \\
\text { антителом }\end{array}$ & $\begin{array}{c}\text { Срезы для } \\
\text { положительного } \\
\text { контроля антигена }\end{array}$ \\
\hline IgG & $\begin{array}{c}\text { Sigma-Aldrich } \\
\text { CMC26530021 }\end{array}$ & $1: 100$ & 30 мин., $+37^{\circ} \mathrm{C}$ & миндалина \\
\hline IgE & Abcam ab66043 & $1: 100$ & 30 мин, $+37^{\circ} \mathrm{C}$ & миндалина \\
\hline TGF- $\beta$ & Abcam ab 66043 & $1: 100$ & 16 ч, $+4^{\circ} \mathrm{C}$ & плацента \\
\hline $\mathrm{CD} 1 \alpha$ & Dako Clone 010 & $1: 50$ & 30 мин., $+37^{\circ} \mathrm{C}$ & миндалина \\
\hline $\mathrm{CD} 4$ & Dako Clone 4B/12 & $1: 50$ & 30 мин., $+37^{\circ} \mathrm{C}$ & миндалина \\
\hline $\mathrm{CD} 8$ & Dako Clone C8/144B & $1: 50$ & 30 мин., $+37^{\circ} \mathrm{C}$ & миндалина \\
\hline
\end{tabular}

нения воспалительная инфильтрация дермы и признаки васкулита отсутствовали. Изменения эпителия в виде спонгиоза и внутриклеточного отека, отека дермы встречались в единичных случаях, по частоте 


\section{Оригинальные исследования}

и интенсивности не отличались от наблюдений при АД.

На рисунках 1-3 приведены микрофотографии атопической кожи с характерными изменениями.

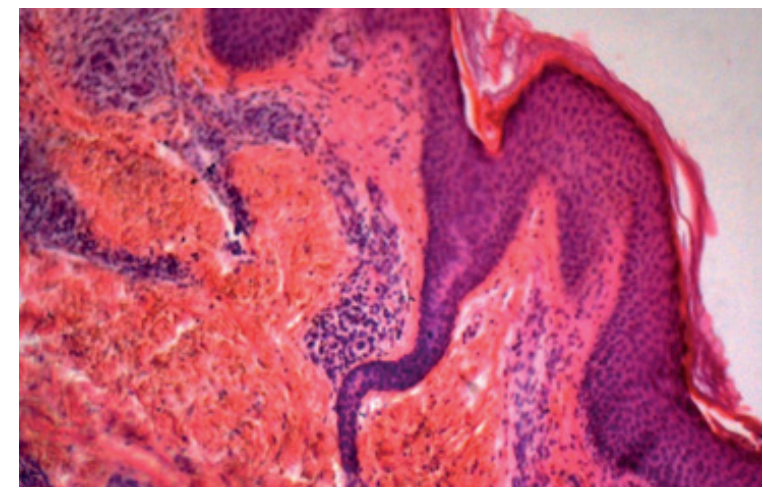

Рисунок 1. - Атопический дерматит. Воспалительная инфильтрация в верхних слоях дермы, акантоз и гиперкератоз. Окраска гематоксилином и эозином, $\times 200$

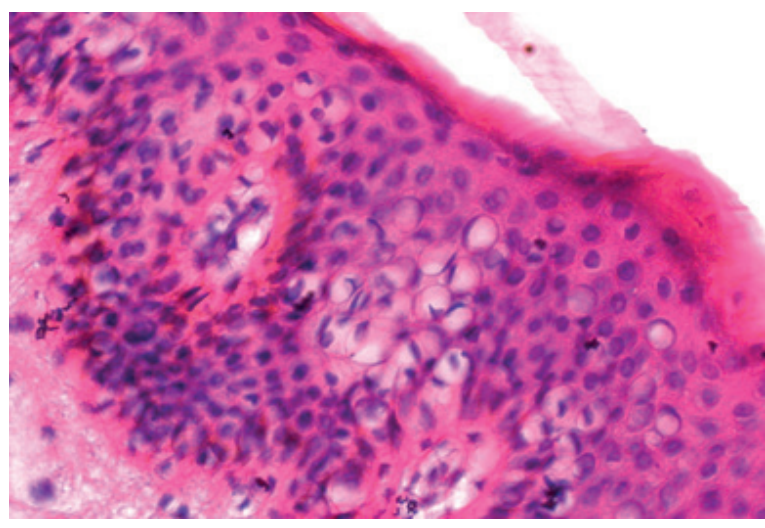

Рисунок 2. - Атопический дерматит. Внутриклеточный отек эпидермиса. Окраска гематоксилином и эозином, $\times 200$

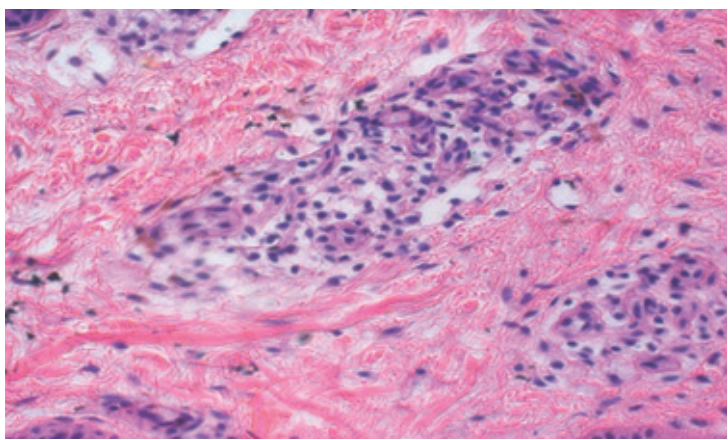

Рисунок 3. - Атопический дерматит. Периваскулярная лимфо-плазмоцитарная инфильтрация и отек дермы.

Окраска гематоксилином и эозином, $\times 200$

На рисунках 4-9 приведены микрофотографии атопической кожи с экспрессией иммуногистохимических маркёров.

Сравнение частоты изученных гистологических и иммуногистохимических параметров у детей, страдающих АД, и в группе сравнения, приведены в таблице 2 .

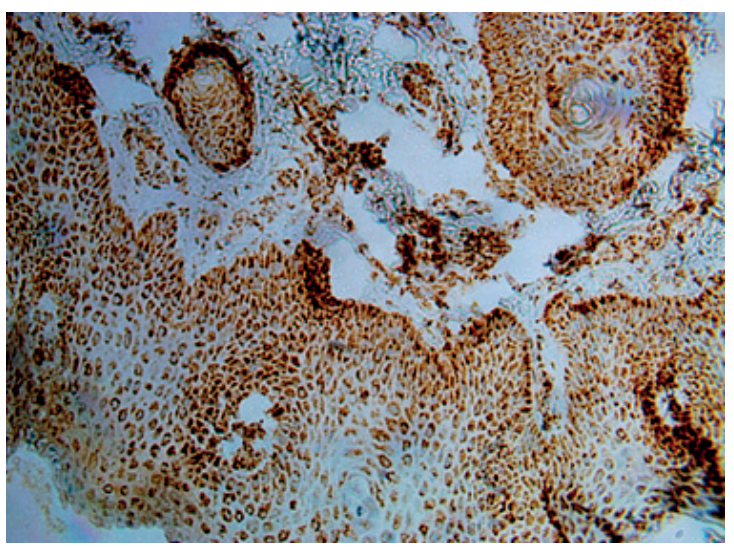

Рисунок 4. - Экспрессия TGFß в атопической коже. Окраска с использованием антител к TGFß. ×100

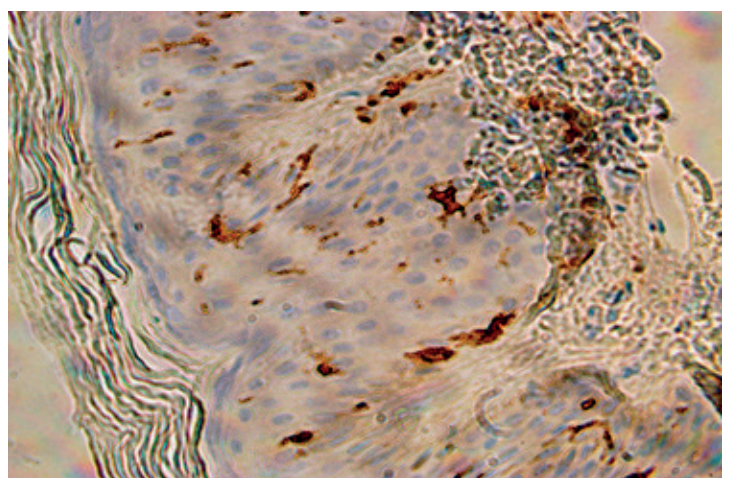

Рисунок 5. - Экспрессия CD1а в атопической коже. Окраска с использованием антител к CD1a, ×100

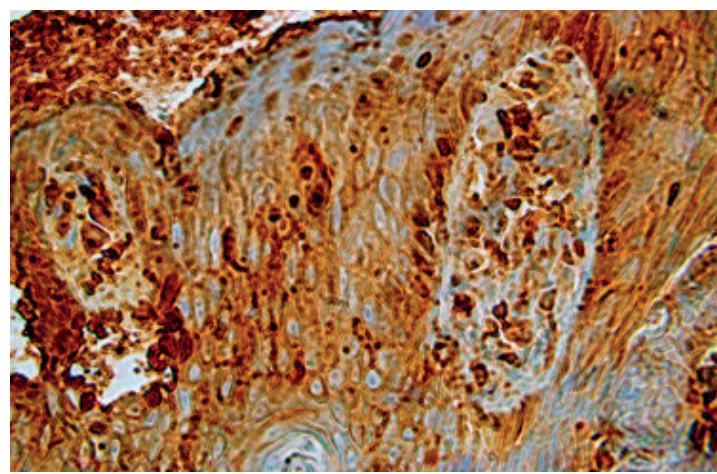

Рисунок 6. - Экспрессия IgG в атопической коже. Окраска с использованием антител к IgG, х100

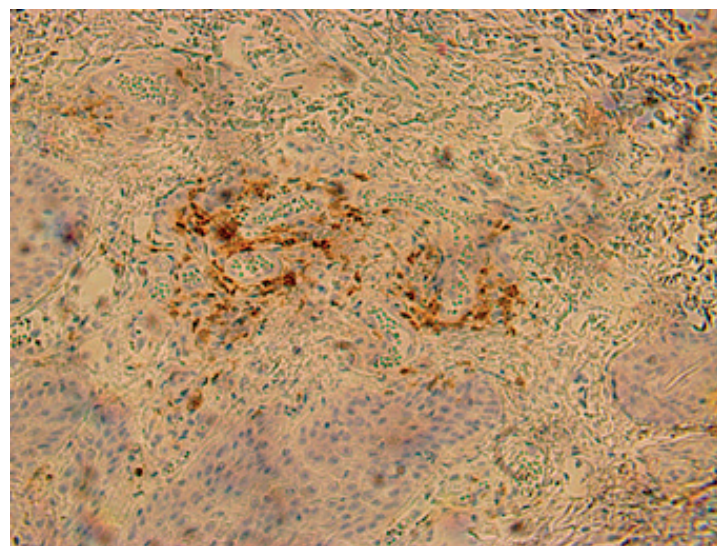

Рисунок 7. - Экспрессия CD4 в атопической кожее. Окраска с использованием антител к CD4, х100 


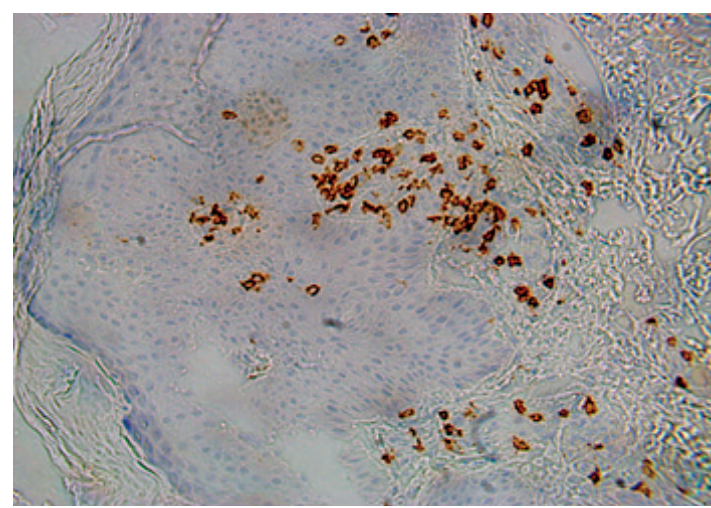

Рисунок 8. - Экспрессия CD8 в атопической коже. Окраска с использованием антител к CD8, х100

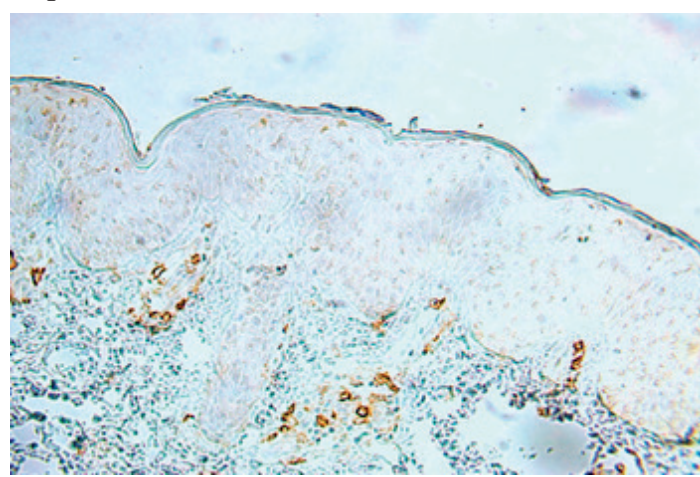

Рисунок 9. - Экспрессия IgE в атопической коже.

Окраска с использованием антител к IgE, х100

Tаблица 2. - Частота гистологических и иммуногистохимических параметров у детей, страдающих АД, и в группе сравнения

\begin{tabular}{|c|c|c|c|}
\hline \multirow{2}{*}{ Признак } & \multicolumn{2}{|c|}{ Доля образцов, имевших признак, \% } & \multirow{2}{*}{$\begin{array}{c}\text { Уровень } \\
\text { значимости, } p\end{array}$} \\
\hline & АД & группа сравнения & \\
\hline Клеточный инфильтрат & $88,0(75,3-100,0)$ & $25,5(13,1-37,9)$ & 0,00001 \\
\hline Признаки васкулита & $68,0(49,8-86,2)$ & $21,2(9,6-32,8)$ & 0,0002 \\
\hline Отёк дермы & $72,0(54,4-89,6)$ & $51,0(36,8-65,2)$ & $>0,05$ \\
\hline Внутриклеточный отёк & $16,0(1,7-30,3)$ & $4,2(0,0-9,9)$ & $>0,05$ \\
\hline Спонгиоз & $4,0(0,0-11,6)$ & $8,7(0,7-16,7)$ & $>0,05$ \\
\hline Акантоз & $84,0(69,7-98,3)$ & $31,9(18,6-45,2)$ & 0,0001 \\
\hline Склероз & $80,0(64,4-95,6)$ & $57,4(43,3-61,5)$ & 0,05 \\
\hline Гиперкератоз & $64,0(45,2-82,8)$ & $55,5(43,3-69,7)$ & $>0,05$ \\
\hline Нейтрофилы & 0,0 & 0,0 & $>0,05$ \\
\hline Плазмоциты & $36,0(17,2-54,8)$ & $4,2(0,0-9,9)$ & 0,0006 \\
\hline Эозинофилы & 0,0 & 0,0 & $>0,05$ \\
\hline $\operatorname{IgE~эпидермис~}$ & $50,0(19,1-80,9)$ & $46,1(27,0-65,2)$ & $>0,05$ \\
\hline $\operatorname{IgE~дерма~}$ & $90,0(71,5-100,0)$ & $46,1(27,0-65,2)$ & 0,02 \\
\hline IgG эпидермис & 100,0 & $75,0(59,0-91,0)$ & 0,04 \\
\hline IgG дерма & 100,0 & 0,0 & 0,00001 \\
\hline CD1+ эпидермис & 100,0 & 0,0 & 0,00001 \\
\hline CD1+ дерма & 100,0 & 0,0 & 0,00001 \\
\hline CD4+ эпидермис & $38,4(12,0-64,8)$ & $3,6(0,0-10,5)$ & 0,005 \\
\hline CD4+ дерма & $46,1(19,1-73,1)$ & 0,0 & 0,0004 \\
\hline CD8+ эпидермис & $45,4(16,0-74,8)$ & $6,1(0,0-14,2)$ & 0,003 \\
\hline CD8+ дерма & 100,0 & $6,1(0,0-14,2)$ & 0,00001 \\
\hline TGF $\beta+$ эпидермис & 100,0 & 100,0 & $>0,05$ \\
\hline TGF $\beta+$ дерма & 100,0 & 0,0 & 0,00001 \\
\hline
\end{tabular}

Таким образом, как отражено в таблице 2, $100 \%$ образцов атопической кожи были позитивны по IgG, CD1 и TGF $\beta$ в дерме, в то время как неатопическая кожа негативна по этим маркерам. Существенно чаще наблюдались клеточный инфильтрат, акантоз, признаки васкулита и плазмоцитарная инфильтрация, а также позитивность дермы по IgE, CD4, 8 и эпидермиса по CD4 ( $<0,05)$. Характерно отсутствие нейтрофилов и эозинофилов в образцах как поражённой, так и здоровой кожи.

Как видно из таблицы 3, выраженность внутриклеточного отёка, отёка дермы, спонгиоза и экспрессии IgE и CD4 и CD8 в эпидермисе в коже у детей, страдающих АД, и группы сравнения не различалась ( $>00,05)$. Остальные показатели были более выражены в образцах атопической кожи $(\mathrm{p}<0,05)$.

В таблице 4 представлены существенные корреляционные связи между иммуногистохимическими показателями и клиническими особенностями.

Примечательно, что интенсивность инфильтрации кожи плазмоцитами коррелирует с наличием аллергического ринита $(\mathrm{R}=-0,39, \mathrm{p}=0,04)$, а выраженность инфильтрации эпителия CD8+ клетками - с наличием патологии поджелудочной железы $(\mathrm{R}=-0,69, \mathrm{p}=0,01)$ и с эритематозно-сквамозной формой дерматита $(\mathrm{R}=-0,63$, $\mathrm{p}=0,03)$.

При выраженности инфильтрации 3 балла корки к моменту выписки были у 50,0 (1,0-99,0)\% детей, в то время как при меньшей выраженности инфильтрации они отсутствовали у всех детей $(p=0,04)$. При выраженности инфильтрации 3 балла пигментные пятна встречались в $66,7(13,4-100,0) \%$ случаев, что существенно чаще, чем при выраженности инфильтрации 1 балл $(0,0 \%)(p=0,02)$. У детей без гиперкератоза АД лёгкой степени на момент выписки наблюдался в 100,0\% случаев, в то время как при наличии гиперкератоза он установлен лишь у $50,0(25,5-74,5) \%, \mathrm{p}=0,04)$.

При наличии в инфильтрате плазмоцитов интенсивность зуда при первичном осмотре была существенно больше $8,0(8,0-10,0)$ баллов, чем при их отсутствии - 5,0 (3,0-8,0) баллов $(p=0,01)$. Поэтому при наличии в инфильтрате плазмоцитов сумма баллов блока «С» была достоверно больше - 12,0 $(10,0-18,0)$ баллов, чем при их отсутствии - 9,0 (5,0-10,5) баллов $(\mathrm{p}=0,01)$. Динамика лихенификации достоверно ассоциирована с выраженностью инфильтрации плазмоцитами 
Таблица 3. - Выраженность морфологических и иммуногистохимических признаков у детей, страдающих АД, и группы сравнения

\begin{tabular}{|c|c|c|c|}
\hline \multirow{2}{*}{ Признак } & \multicolumn{2}{|c|}{ Выраженность, баллы } & \multirow{2}{*}{$\begin{array}{c}\text { Уровень } \\
\text { значимости, }\end{array}$} \\
\hline & АД & группа сравнения & \\
\hline Клеточный инфильтрат & $2,0(1,0-2,0)$ & $0,0(0,0-1,0)$ & 0,0000009 \\
\hline Признаки васкулита & $1,0(0,0-2,0)$ & $0,0(0,0-0,0)$ & 0,00005 \\
\hline Отёк дермы & $1,0(0,0-2,0)$ & $1,0(0,0-1,0)$ & $>0,05$ \\
\hline Внутриклеточный отёк & $0,0(0,0-0,0)$ & $0,0(0,0-0,0)$ & $>0,05$ \\
\hline Спонгиоз & $0,0(0,0-0,0)$ & $0,0(0,0-0,0)$ & $>0,05$ \\
\hline Акантоз & $1,0(1,0-2,0)$ & $0,0(0,0-1,0)$ & 0,00004 \\
\hline Гиперкератоз & $1,0(0,0-2,0)$ & $0,0(0,0-1,0)$ & 0,04 \\
\hline Склероз & $2,0(1,0-2,0)$ & $1,0(0,0-1,0)$ & 0,001 \\
\hline Нейтрофилы & - & - & - \\
\hline Плазмоциты & $0,0(0,0-1,0)$ & $0,0(0,0-0,0)$ & 0,02 \\
\hline Эозинофилы & - & - & - \\
\hline IgE эпидермис & $0,5(0,0-2,0)$ & $0,0(0,0-2,0)$ & $>0,05$ \\
\hline IgE дерма & $2,0(1,0-2,0)$ & $0,0(0,0-1,0)$ & 0,0006 \\
\hline IgG эпидермис & $2,5(2,0-3,0)$ & $1,0(0,5-1,0)$ & 0,000003 \\
\hline IgG дерма & $3,0(3,0-3,0)$ & $0,0(0,0-0,0)$ & 0,0000009 \\
\hline CD1+ эпидермис & $2,5(2,0-3,0)$ & $2,0(1,0-2,0)$ & 0,0005 \\
\hline CD1+ дерма & $2,5(1,0-3,0)$ & $0,0(0,0-0,0)$ & 0,0000009 \\
\hline CD4+ эпидермис & $0,0(0,0-3,0)$ & $0,0(0,0-0,0)$ & $>0,05$ \\
\hline CD4+ дерма & $0,0(0,0-2,0)$ & $0,0(0,0-0,0)$ & 0,01 \\
\hline CD8+ эпидермис & $0,0(0,0-1,0)$ & $0,0(0,0-0,0)$ & 0,05 \\
\hline CD8+ дерма & $2,0(2,0-3,0)$ & $0,0(0,0-0,0)$ & 0,0000009 \\
\hline TGF $\beta+$ эпидермис & $3,0(3,0-3,0)$ & $2,0(2,0-2,0)$ & 0,0000009 \\
\hline TGF $\beta+$ дерма & $3,0(3,0-3,0)$ & $0,0(0,0-0,0)$ & 0,0000009 \\
\hline
\end{tabular}

Таблица 4. - Корреляционные связи между иммуногистохимическими показателями и клиническими особенностями

\begin{tabular}{|c|c|c|c|c|}
\hline \multicolumn{2}{|c|}{ Коррелируемые переменные } & \multirow{2}{*}{$\begin{array}{c}\text { Количество, } \\
\mathrm{n}\end{array}$} & \multirow{2}{*}{$\begin{array}{c}\text { Spearmen, } \\
\text { R }\end{array}$} & \multirow{2}{*}{$\begin{array}{c}\text { Уровень } \\
\text { значимости, } \\
\text { p } \\
\end{array}$} \\
\hline $\begin{array}{l}\text { Показатель } \\
\text { клинический }\end{array}$ & $\begin{array}{c}\text { Показатель } \\
\text { морфологический }\end{array}$ & & & \\
\hline Эритема 2 (баллы) & IgE+ эпидермис (баллы) & 10 & $-0,67$ & 0,03 \\
\hline Папулы 2 (баллы) & Отёк дермы (баллы) & 25 & 0,40 & 0,04 \\
\hline Папулы 2 (баллы) & IgE+ эпидермис (баллы) & 10 & 0,68 & 0,02 \\
\hline Эритема 2 (баллы) & $\operatorname{IgE}+$ дерма (баллы) & 10 & $-0,71$ & 0,02 \\
\hline $\begin{array}{l}\text { Нарушение сна } 1 \\
\text { (баллы) }\end{array}$ & IgE+ эпидермис (баллы) & 10 & $-0,70$ & 0,02 \\
\hline Зуд 2 (баллы) & IgG+ эпидермис (баллы) & 14 & $-0,54$ & 0,04 \\
\hline С 2 (баллы) & IgG+ эпидермис (баллы) & 14 & $-0,56$ & 0,03 \\
\hline В 1 (баллы) & CD4+ эпидермис (баллы) & 13 & $-0,55$ & 0,04 \\
\hline $\begin{array}{l}\text { Динамика сухости } \\
\text { (баллы) }\end{array}$ & CD4+ дерма (баллы) & 13 & $-0,58$ & 0,03 \\
\hline Папулы 2 (баллы) & CD1+ эпидермис (баллы) & 10 & $-0,65$ & 0,03 \\
\hline Эритема (наличие) & CD8+ дерма (баллы) & 8 & 0,73 & 0,03 \\
\hline Эритема 2 (баллы) & CD8+ дерма (баллы) & 9 & 0,78 & 0,01 \\
\hline Зуд 2 (баллы) & CD8+ эпидермис (баллы) & 11 & 0,60 & 0,04 \\
\hline С 2 (баллы) & CD8+ эпидермис (баллы) & 11 & 0,60 & 0,04 \\
\hline
\end{tabular}

$(\mathrm{p}=0,03)$. При уменьшении выраженности лихенификации на 1 балл выраженность инфильтрации плазмоцитами составляла $1,0(1,0-1,0)$ балл, a при отсутствии динамики лихенификации инфильтрация была значимо менее выраженной - $0,0(0,0-0,5)$ баллов.

Инфильтрация CD4+ клетками дермы не определялась при наличии папул, в то время как при их отсутствии она не определялась лишь в 16,6\% случаев (95\% ДИ 0,0-46,3) $(\mathrm{p}=0,01)$. При наличии папул выраженность инфильтрации дермы CD4+ клетками была значимо меньше $(0,0)(0,0$ $0,0)$, чем при их наличии $(2,0$ $(1,0-3,0) \mathrm{p}=0,01)$. Экспрессии CD4+ клеток в дерме не наблюдалось в 100\% случаев у детей без эритематозно-сквамозной формы АД, в то время как у 83,3\% (95\% ДИ 53,5$100,0)$ детей диагностировалась упомянутая клиническая форма АД при экспрессии CD4+ $(p=0,01)$. Верна и обратная картина. У всех детей c эритематозно-сквамозной формой наблюдалась инфильтрация дермы CD4+ клетками и лишь в 12,5\% (95\% ДИ 0,0$35,4)$ она присутствовала при других клинических формах $(\mathrm{p}=0,01)$.

Динамика индекса SCORAD была существенно больше у детей без инфильтрации CD4+ клетками эпидермиса $(35,0 \quad(18,0-46,5)$ баллов), чем при её наличии $(11,0 \quad(6,0-20,0)$ баллов $\mathrm{p}=0,04)$; это связано с тем, что при отсутствии инфильтрации эпидермиса сумма баллов SCORAD на момент первичного осмотра составила 50,5 (40,0-62,5), а при её наличии - 33,0 (31,0-36,0) $(\mathrm{p}=0,02)$. Вполне закономерно, что при наличии экспрессии CD4+ динамика блока «В» как абсолютная, так и относительная, существенно различалась. Абсолютная динамика при выявлении CD4+ клеток составляла 2,0 (1,0$2,0)$ балла, что существенно меньше, чем при их отсутствии $(5,5)(3,5-6,0)$ балла, $\mathrm{p}=0,006)$. Относительная же динамика блока «В» при выявлении $\mathrm{CD} 4+$ клеток составляла $66,6 \quad(42,8-77,7) \%$, что существенно меньше, чем при их отсутствии $(63,3(52,2-79,2) \%, \mathrm{p}=0,01)$. Кроме того, динамика сухости кожи была суще- 
ственно больше у детей при отсутствии инфильтрации CD4+ клетками эпидермиса $(1,0)(1,0-1,0)$ балл), чем при их наличии $(0,0(0,0-0,0)$ баллов, $\mathrm{p}=0,04)$. Различалась также динамика сна при отсутствии инфильтрации CD4+ клетками эпидермиса $(2,0(1,5-5,5)$ балла) и при её наличии $(1,0$ $(1,0-1,0)$ балл, $\mathrm{p}=0,04)$.

Чешуйки встречались у $100 \%$ детей, если инфильтрации эпидермиса CD4+ клетками не наблюдалось, и лишь у 20,0\% (95\% ДИ 0,0-55,0), когда в эпидермисе определялись CD4+ клетки $(\mathrm{p}=0,01)$. Во всех случаях при отсутствии чешуек на коже наблюдалась экспрессия CD4+ в эпидермисе, в то время как при их наличии - лишь в $12,5 \%(95 \%$ ДИ $0,0-35,4)(\mathrm{p}=0,01)$ случаев. При наличии чешуек выраженность инфильтрации эпидермиса CD4+ клетками составила $0,0(0,0$ $0,0)$, а при их отсутствии - 3,0 $(3,0-3,0)$ балла $(\mathrm{p}=0,01)$.

Площадь поражённой кожи на момент первичного осмотра была существенно больше при отсутствии в эпидермисе CD8+ клеток $(82,7$ $(58,5-100,0))$, чем при их наличии $(31,5(31,5-$ $36,0)$ баллов, $\mathrm{p}=0,03)$. При отсутствии IgЕ в эпидермисе нарушения сна на момент первичного осмотра были более выражены $(8,0(3,0-8,0))$, чем при его наличии $(1,0(1,0-2,0)$ балл, $p=0,03)$.

В таблице 5 представлены существенные корреляционные связи между показателями биоптата.

Tаблица 5. - Корреляционные связи между показателями биоптата

\begin{tabular}{|c|c|c|c|c|}
\hline \multicolumn{2}{|c|}{ Коррелируемые переменные } & \multirow{2}{*}{$\begin{array}{c}\text { Количество, } \\
\text { n }\end{array}$} & \multirow{2}{*}{$\begin{array}{c}\text { Spearmen, } \\
\mathrm{R}\end{array}$} & \multirow{2}{*}{$\begin{array}{c}\text { Уровень } \\
\text { значимости, } p\end{array}$} \\
\hline Показатель 1 & Показатель 2 & & & \\
\hline IgE+ эпидермис (баллы) & CD8+ дерма (баллы) & 5 & $-0,88$ & 0,04 \\
\hline IgE+ эпидермис (баллы) & CD1+ дерма (баллы) & 7 & $-0,90$ & 0,004 \\
\hline IgE+ эпидермис (баллы) & $\begin{array}{c}\text { CD1+ эпидермис } \\
\text { (баллы) }\end{array}$ & 6 & $-0,93$ & 0,006 \\
\hline IgE+ эпидермис (баллы) & плазмоциты (баллы) & 8 & $-0,70$ & 0,04 \\
\hline IgE+ дерма (баллы) & гиперкератоз (баллы) & 8 & 0,74 & 0,03 \\
\hline $\begin{array}{l}\text { CD4+ эпидермис } \\
\text { (баллы) }\end{array}$ & $\begin{array}{c}\mathrm{IgG}+\text { эпидермис } \\
\text { (баллы) }\end{array}$ & 12 & $-0,58$ & 0,04 \\
\hline CD4+ дерма (баллы) & CD1+ дерма (баллы) & 9 & $-0,71$ & 0,03 \\
\hline Инфильтрат (баллы) & CD8+ дерма (баллы) & 8 & 0,70 & 0,04 \\
\hline
\end{tabular}

Как видно из таблицы 5 , между морфологическими показателями биоптата существуют значимые ассоциации.

При наличии склеротических изменений кожи количество IgG в эпидермисе было суще-

\section{Литература}

1. Жерносек, В. Ф. Атопический дерматит / В. Ф. Жерносек, Т. П. Дюбкова // Аллергические заболевания у детей : руководство для врачей / В. Ф. Жерносек, Т. П. Дюбкова. - Минск : Новое знание, 2003. - Гл. 4. C. 241-274.

2. WAO White Book of Allergy 2013 [Electronic resource] // Mode of access: http://www.worldallergy.org/UserFiles/ ственно больше $(3,0(2,0-3,0)$ балла), чем при отсутствии таковых $(1,0(1,0-2,0)$ балл, $\mathrm{p}=0,02)$. При наличии гиперкератоза экспрессия CD4+ рецептора в эпидермисе наблюдалась в $22,2 \%$ (95\% ДИ 0,0-49,3) случаев, а при его отсутствии - в $100,0 \%(\mathrm{p}=0,03)$. При наличии инфильтрации CD4+ клетками эпидермиса гиперкератоз наблюдался в 40,0\% (95\% ДИ 0,0-82,9) случаев, при её отсутствии - в 100,0\% (p=0,03).

\section{Выводы}

1. При микроскопическом исследовании кожи у детей с АД в отличие от группы сравнения достоверно чаще наблюдались лимфоплазмоцитарная инфильтрация дермы с признаками васкулита, склеротические изменения и акантоз эпителия $(\mathrm{p}<0,05)$.

2. К иммуногистохимическим признакам АД следует отнести $100 \%$ позитивность по IgG, CD1 и TGF $\beta$ в дерме, в то время как неатопическая кожа была негативна по данным маркерам. Существенно чаще наблюдались позитивность $\mathrm{IgG}, \mathrm{CD} 1$, по CD4+, TGF $\beta$ в эпидермисе и по $\mathrm{IgE}$, CD4, CD8 в дерме $(\mathrm{p}<0,05)$.

3. Экспрессия IgE + и CD8+ маркеров в эпидермисе является признаком благоприятного клинического течения АД у детей, поскольку они тесно ассоциированы с меньшей интенсивностью зуда и площадью поражения кожи $(p=0,03$ в обоих случаях).

4. Инфильтрацию дермы CD4+ лимфоцитами можно считать гистологическим маркером эритематозно-сквамозной формы заболевания, поскольку она наблюдается в $100 \%$ случаев, а при прочих клинических формах лишь в $12,5 \%$ $(95 \%$ ДИ $0,0-35,4)(\mathrm{p}=0,01)$.

5. Наличие инфильтрации CD4+ клетками эпидермиса можно считать благоприятным признаком, так как сумма баллов SCORAD на момент первичного осмотра при наличии инфильтрации $\mathrm{CD} 4+$ клетками эпидермиса существенно меньше $(33,0$ (31,0$36,0))$, чем при её наличии $(50,5(40,0-62,5), \quad \mathrm{p}=0,02)$. $\mathrm{B}$ связи с этим динамика индекса SCORAD была существенно меньше у детей с инфильтрацией CD4+ клетками эпидермиса $(11,0(6,0-20,0))$, чем при её наличии $(35,0(18,0-46,5), \mathrm{p}=0,04)$.

file/WAO-White-Book-on-Allergy.pdf. - Date of access: 04.04.2013.

3. Eczema [Electronic resource] // Mode of access: https:// www.aad.org/media/stats/conditions/eczema/. - Date of access: 19.09.2017.

4. Хоха, Р. Н. Атопический дерматит у детей: тренды общей заболеваемости / Р. Н. Хоха, Н. С. Парамонова, Н. А. Малышко // Здравоохранение. - 2016. - № 1. - С. 11-17. 
5. Хоха, Р. Н. Факторы макроуровня, влияющие на показатель заболеваемости атопическим дерматитом / Р. Н. Хоха // Журнал Гродненского государственного медицинского университета. - 2017. - Т. 3, № 3. - С. 301-305. - doi: 10.25298/2221-8785-2017-15-3-301-305.

6. Мяделец, О. Д. Морфофункциональная дерматология / О. Д. Мяделец, В. П. Адаскевич. - Москва : Медицинская литература, 2006. -752 с.

7. Патоморфология болезней кожи : руководство для врачей / Г. М. Цветкова [и др.]. - Москва : Медицина, 2003. -496 c.

8. Кунгуров, Н. В. Особенности клеточного инфильтрата в дерме у больных с различными типами течения атопического дерматита / Н. В. Кунгуров, С. В. Сазонов, М. М. Кохан // Вестник дерматологии и венерологии. 2000. - № 5. - С. 40-46.

9. Кунгуров, Н. В. Особенности пролиферативных процессов в эпидермисе больных с различными типами течения атопического дерматита / Н. В. Кунгуров, С. В. Сазонов, М. М. Кохан // Вестник дерматологии и венерологии. - 2000. - № 4. - С. 24-27.

10. Клинические протоколы диагностики и лечения детей c аллергическими заболеваниями [Электронный ресурс] / Министерство здравоохранения Республики Беларусь. - Минск, 2014. - Режим доступа: http://minzdrav. gov.by/dadvfiles/000913_270327_829.pdf. - Дата доступа: 14.10.2016.

11. Severity scoring of atopic dermatitis: the SCORAD index / Consensus Report of the European Task Force on Atopic Dermatitis // Dermatology. - 1993. - Vol. 186. - P. 23-31. doi: $10.1159 / 000247298$.

\section{References}

1. Zhernosek VF, Djubkova TP. Atopicheskij dermatit [Atopic dermatitis]. In: Zhernosek VF, Djubkova TP. Allergicheskie zabolevanija $u$ detej [Allergic diseases in children]. Minsk: Novoe znanie; 2003. Ch. 4; p. 241-274. (Russian).

2. WAO White Book of Allergy 2013 [Internet]. Available from: http://www.worldallergy.org/UserFiles/file/WAO-WhiteBook-on-Allergy.
3. Eczema [Internet]. Available from: https://www.aad.org/ media/stats/conditions/eczema/.

4. Hoha RN, Paramonova NS, Malyshko NA. Atopicheskij dermatit u detej: trendy obshhej zabolevaemosti [Atopic dermatitis in children: trends in total incidence]. Zdravoohranenie [Health]. 2016;(1):11-17. (Russian).

5. Hoha RN, Faktory makrourovnja, vlijajushhie na pokazatel zabolevaemosti atopicheskim dermatitom [Macro-level factors affecting the incidence of atopic dermatitis]. Zhurnal Grodnenskogo gosudarstvennogo medicinskogo universiteta [Journal of the Grodno State Medical University]. 2017;3(3): 301-305. doi: 10.25298/2221-8785-2017-15-3-301-305. (Russian).

6. Mjadelec OD, Adaskevich VP. Morfofunkcionalnaja dermatologija [Morphological dermatology]. Moskva: Medicinskaja literatura; 2006. 752 p. (Russian).

7. Cvetkova GM, Mordovceva VV, Vavilov AM, Mordovcev VN. Patomorfologija boleznej kozhi [Pathomorphology of skin diseases]. Moskva: Medicina; 2003. 496 p. (Russian).

8. Kungurov NV, Sazonov SV, Kohan MM. Osobennosti kletochnogo infiltrata $\mathrm{v}$ derme u bolnyh s razlichnymi tipami techenija atopicheskogo dermatita [Features of the cellular infiltrate in the dermis of patients with different types of the course of atopic dermatitis]. Vestnik dermatologii $i$ venerologii [Bulletin of dermatology and venereology]. 2000;(5):40-46. (Russian).

9. Kungurov NV, Sazonov SV, Kohan MM. Osobennosti proliferativnyh processov $\mathrm{v}$ jepidermise bolnyh s razlichnymi tipami techenija atopicheskogo dermatita [Features of proliferative processes in epidermis of patients with different types of atopic dermatitis]. Vestnik dermatologii $i$ venerologii [Bulletin of dermatology and venereology]. 2000;(4):24-27. (Russian).

10. Ministerstvo zdravoohraneniya Respubliki Belarus. Klinicgeskij protocol diagnostiki, lecheniya i profilaktiki atopicheskogo dermatita [Clinical guideline for diagnostic, treatment and prevention of atopic dermatitis]. Available from: http://minzdrav.gov.by/dadvfiles/000913_270327_829.pdf. (Russian).

11. Consensus Report of the European Task Force on Atopic Dermatitis. Severity scoring of atopic dermatitis: the SCORAD index. Dermatology. 1993;186(1):23-31. doi: $10.1159 / 000247298$.

\title{
CLINICAL AND MORPHOLOGICAL CHARACTERISTIC OF THE SKIN IN CHILDREN WITH ATOPIC DERMATITIS
}

\author{
Bedin P. G., Lialikov S. A., Basinskiy V. A., Marszalek Andrzej, Shtabinskaya T. T., \\ Aleksinskiy V. S. \\ Educational Institution "Grodno State Medical University", Grodno, Belarus \\ Medical Academy "Ludwik Rydygier" in Bydgoszcz, Poland
}

\begin{abstract}
Background. Atopic dermatitis (AD) is an actual problem of pediatrics due to its wide prevalence.
The aim is to give clinical and morphological characteristic of the skin in children with AD and reveal its relationship with clinical manifestations.

Material and methods. Morphological and immunohistochemical study of 27 biopsies of atopic and 48 biopsies of non-atopic skin was carried out.

Results. Expression of IgE and CD8 in the epidermis is a favorable sign, since the intensity of itching and the area of skin lesions is less ( $p=0.03$ in both cases). 100\% of samples of the erythematous-squamous form were infiltrated with CD4+ in derma, which is more common than in other clinical forms $(p=0.01)$. The dynamics of the SCORAD was greater in children without infiltration of CD4 cells in the epidermis $(p=0.04)$ due to the higher initial amount of SCORAD points $(p=0.02)$.

Conclusions. Morphological and immunohistochemical markers are significantly associated with clinical features of $A D$.
\end{abstract}

Keywords: atopic dermatitis, skin, morphology, children. 